\title{
Stress and water consumption in a reptile'
}

IRH'N M. SPIGET aHd ALEX R.1.HS.1) University of Toromo. Toronto 5 . Canala

Electric shock administered to the painted rurte' (hrysemys outside the drinking situation failed in any' general wa. to affect water intake in differentially hydrated Ss, nor did such treatment disturb the rather precise aquastatic mechonism homonstrated by this species. Deprived turtles did, however, tend to consume more water than controls when some degree of familiarity with the drinking surround had been obtained. Although shock adminis tered within the watcr-alailable situation likewise failed to produce a general drinking deficit, initial intake by' nondeprived Ss was reduced, and the first indication of a disturbance in the water-regulatory mechanism was c hserved.

It has been shown that shock-induced stress has been consistently accompanied by increased urinary sodium and potassium in fresh water turtles (Spigel \& Ramsay, in press). Other experiments (Spigel \& Ellis, 1968) have shown a very precise relationship between antecedent water deprivation and drinking in the turtle Chrysemys picta marginata. The initial water intake of Ss following 72-h dehydration was equal to the total consumption by nondeprived Ss over 3 days. The same precision was evident for 48-h deprived Ss as compared with the 2-day drinking of a nondeprived group. The current experiments sought to examine the consequences of shock stress on this species' rather precise water-regulatory mechanism.

\section{EXPERIMENT 1}

Subjects

Sixty-four male, fresh water turtles (Chrysemys picta marginata) were used. They ranged in age between 4 and 5 years as estimated from carapace length.

Apparatus

This consisted of four identical plywood Y-mazes described elsewhere (Spigel, Ellis, \& Kaiser, 1967). In each arm of the maze were two $30-\mathrm{ml}$ plastic cups which permitted free drinking by Ss without body immersion.

\section{Procedure}

Subjects were divided into two major groups: nondeprived and 72-h deprived. Under the deprived condition, Ss were placed in a dry glass tank $72 \mathrm{~h}$ prior to the onset of the testing days. Of the $32 \mathrm{Ss}$ in this group, eight received shock commencing immediately after placement in the maze (Day I Ss), eight Ss were given shock after
$24 \mathrm{~h}$ (Day $2 \mathrm{Ss}$ ). and eight Ss after $48 \mathrm{~h}$ (Day 3 Ss): eight Ss received no shock on any day (No-Shock Ss). Nondeprived Ss were placed directly from the home tank into the maze situation. These Ss were divided into Day 1, Day 2, Day 3, and No-Shock subgroups as in the deprived condition. All Ss were randomly assigned to the eight experimental and control subgroups.

A total of four Ss, two from each of the major groups, were run during each 3-day experimental period. Each $S$ was placed in the stem of the Y-maze and then either removed for shock treatment or left alone. The $30 \mathrm{ml}$ cups were filled with distilled water and the amount consumed by each $S$ was measured every $24 \mathrm{~h}$. The cups were refilled after each measurement.

A 20-V shock, generated by a variable ac transformer, was administered on shock days by removing the $S$ from the maze and attaching alligator clips to the tail and one leg. Shock treatment consisted of $103-\mathrm{sec}$ impulses every $15 \mathrm{~min}$ for the first $2 \mathrm{~h}$, and 5 3-sec impulses every $15 \mathrm{~min}$ for the third hour. Following each shock treatment Ss were replaced in the stem of the maze.

\section{Results}

Comparison of Day 1 scores of 72-h deprived and nondeprived $S s$ indicated that deprivation affected Day 1 water consump. tion. Although Day 2 scores for deprived and nondeprived $\mathrm{Ss}$ were significantly different, the Day 2 scores for the deprived Ss were not significantly different from either nondeprived Day 1 or nondeprived Day 3 scores. Day 3 scores for deprived and nondeprived Ss were also not significantly different.

Nondeprived Ss showed no significant differences in water consumption over days.

Mann-Whitney $U$ tests indicated that Day 1 drinking scores for the deprived Ss were not significantly different from the summed scores for 3 days in nonshocked, nondeprived Ss.

Analysis of variance yielded significant $F$ ratios only for deprivation $(F=69.94$, $\mathrm{df}=1 / 56)$, days $(F=24.20, \mathrm{df}=2 / 112)$, and Deprivation by Days $(\mathrm{F}=12.08$, $\mathrm{df}=2 / 112)$.

\section{EXPERIMENT 2 \\ Subjects}

Forty-eight male Chry'sem!'s picta marginata, 4 to 5 years old as estimated from carapace length, were employed. Subjects were divided randonly into groups of six.

Apparatus

Eight identical, grey. plywood boxes ( 11 $\times 21 \times 10$ in.) were constructed. A slight ramp toward the center of the apparatusled to a $7 \times 11$-in. platform 2 in. above the floor level. In the platform were embedded two $50 \mathrm{ml}$ plastic cups. The cups could be removed for refilling.

\section{Procedure}

The procedure was identical to that of the first experiment except that electric shock was adninistered in the apparatus. On Day 1, alligator clips were attached to the tail and right hind leg, of all the Ss. Wires leading from the clips were taped to the back of the turtle, and then to the shock source.

\section{Results}

As in Experiment 1, an analysis of variance yielded significant differences across deprivation treatments, days, and the Deprivation by Days interaction.

Mann-Whitney U-tests indicated that only the difference between water intake of deprived Ss on Day 1 (shocked Ss drinking less) and the cumulative 3-day consumption of the nondeprived turtles was statistically significant.

Table 1, combining the data of both experiments, contains a comparison of the initial mean water consumption of deprived Ss and the 3-day drinking of nondeprived turtles, the amount consumed by nondeprived Ss shocked within the drinking situation being considerably lower than the three other values.

\section{DISCUSSION}

Investigations with rats have shown that shock-induced stress may lead either to decrease or increase in water consumption, depending upon the experimental procedure (Amsel, 1950; Amsel \& Maltzman, 1950; Amsel \& Cole, 1953; Meyer \& Baenninger, 1963). If Ss are shocked in the drinking situation there is a decrease in water intake. This has been attributed to the conditioning of emotional responses, incompatible with drinking, to the water-available situation. If, however, Ss are shocked outside the drinking situation there is an increase in fluid consumption within the more familiar surround. While the data from the first experiment indicated no overall significant effect of the noxious stimulation on drinking, deprived turtles given shock on Days 2 and 3 still terided to drink considerably more than controls on those days. Since Ss in these experiments were given no opportunity to habituate to the apparatus, these incremental trends which accompanied increasing familiarity with the experimental surround would appear to be consistent with results obtained with rat. (A Mam-Whitney U-test of Day 3 drinking scores for shocked Ss on this day indicated 
lable 1

Comparison of Differentially Deprived Ss Shocked Inside and Outside of Apparatis on Day

\begin{tabular}{lcc} 
& $\begin{array}{c}\text { Day 1 Mean Intake (mil) } \\
\text { of Deprived Ss }\end{array}$ & $\begin{array}{c}\text { 3-day Mean Total Intakc (mi) } \\
\text { of Nondeprived Ss }\end{array}$ \\
Shocked Inside & 24.0 & 14.4 \\
Shocked Outside & 22.8 & 20.8 \\
\hline
\end{tabular}

they were significantly higher than those for nonshocked Ss.) The highly precise water regulatory mechanism proved relatively resistant to shock administration, as deprived Ss' initial drinking was not significantly different from the cumulative 3-day drinking of nondeprived turtles for either controls or those shocked on Day 1.

The data of Experiment 2, however, where Ss were shocked within the apparatus in which they had access to water, revealed trends similar to those in the first experiment with but one possibly important exception.

An observed decrement in Day 1 drinking by nondeprived Ss shocked on this initial day and the fact that only the cumulative water intake by this group was significantly less than the Day 1 consumption by dehydrated Ss similarly shocked, suggested that emotional responses conditioned to cues in the unfarmiliar environment may have attenuated drinking in nondehydrated (and consequently less highly thirstmotivated) turtles. Recovery of a drinking level comparable to $\mathrm{Ss}$ in other groups was not observed until either Day 2 or Day 3. To this extent as well, then, the data are in accord with those of rat in analogous situations, and revealed the first evidence of a breakdown in the water regulatory mechanism so ubiquitously observed in drinking experiments with turtles thus far.

Since earlier investigations into the relation of excretory electrolytes and stress employed nondehydrated $S s$ in novel surrounds, it seemed plausible at first to attribute the elevated concentrations of urinary cations to reduced drinking in shocked turtles. However, it was also the case that residual fluid volume in the habitat of Ss in these earlier studies did not statistically differentiate shocked and nonshocked turtles. Thus, if shocked Ss drank less, they would have had to urinate more to produce equal volumes of residual fluid. But it has also been found in preliminary work that these turtles urinate in proportion to their drinking, suggesting that complex interactions remain to be isolated before the millanisms underlying the stress-induced inciements in excretory sodium and potassium are clearly delineated.

\section{REFERENCES}

AMSIL. A. The effect upon the level of the consummatory response of the additive of anxiety to the motivational complex. Joumal of Experimental Psychology, 1950, 40, 709-715.

AMSEL, A., \& MALTZMAN, I. The effect upon generalized drive strength of emotionality as inferred from the level of the consummatory response. Joumal of Experimental Psychology $1950,40,563-569$

MEYER, K. E., \& BAENNINGER, R. The effect of environmental change and electric shock on water consumption in the rat. Psychological Reports, 1963, 13, 179-185.

SIEGEL, P. S, \& SIEGEL, H. S. The effect of emotionality on the water intake of the rat. Joumal of Comparative \& Physiological Psychology, 1949, 42, 12-16.

SPIGEL, I. M., \& ELLIS, K. R. Electroly te balance and deficit drinking in a reptile. Joumal of Comparative \& Physiological Psychology, 1968, 65, 384-387.

SPIGEL, I. M., ELLIS, K. R., \& KAISER, Y. E. Electroly te balance and drinking in the fresh water turtle. Joumal of Comparative \& Physiological Psychology, 1967, 64, 313-317. SPIGEL, 1. M., \& RAMSAY, A. Excretory electrolytes and the response to stress in a reptile. Joumal of Comparative \& Physiological Psychology, in press. NOTE

1. This research was financed by a grant from the National Research Council of Canada. 